\title{
Smart Roads Geometric Design Criteria and Capacity Estimation Based on AV and CAV Emerging Technologies. A Case Study in the Trans-European Transport Network
}

\author{
Marco Guerrieri ${ }^{1}$ (D) \\ Received: 20 January 2021 / Revised: 21 February 2021 / Accepted: 2 March 2021 / Published online: 19 April 2021 \\ (C) The Author(s) 2021
}

\begin{abstract}
Smart roads, AV and CAV are emerging technologies that represent the new paradigm of mobility. To support the public and private road operators better prepare themselves to implement these technologies in their respective existing or planned infrastructures, there is an urgent need to develop an integrated analysis framework to evaluate the impact of these novel systems on road capacity and safety in function of different market penetration levels of AVs and CAVs. The research focuses on novel smart road geometric design and review criteria based on the performance of AVs and CAVs. The case study of one of the first planned smart roads in Italy has been analysed.
\end{abstract}

Keywords Smart roads $\cdot$ AVs $\cdot$ CAVs $\cdot$ Design criteria $\cdot$ Capacity estimation

\section{Introduction}

Smart roads represent the new paradigm of mobility and aim at being more sustainable, safe, innovative and inclusive, thus modifying the traditional relationship between vehicles, users and infrastructure/environment. Smart roads are digitalized infrastructures increasingly compatible with the new technologies employed in light and heavy vehicles, with specific regard to the more recent Autonomous Vehicles (AVs) and connected and automated vehicles (CAVs). CAVs can monitor multiple vehicles ahead by the vehicle-to-vehicle (V2V) communication.

Basically smart roads adopt cooperative intelligent transportation system technologies (C-ITS) in order to enable the communication and cooperation both among all the vehicles and among the latter and road facilities.

Lately, by means of the C-Roads Platform, many road operators and technical authorities have joined together to harmonise the deployment actions of C-ITS in the European countries. The main objective is the deployment of interoperable cross-border C-ITS services for road users, especially the so-called "Day 1 - C-ITS service".

Marco Guerrieri

marco.guerrieri@unitn.it

1 DICAM, University of Trento, Trento, Italy
In addition to the essential C-ITS technologies, one or more of the following systems can be implemented in smart road Environment (SRE) [1]:

- Lanes dedicated to AVs and CAVs travelling isolated or in platoons;

- Internet of Things (IOT): sensors for monitoring traffic flows, structures (bridges, viaducts, road safety barriers etc.), weather and air pollutants;

- Ramp-metering systems;

- Hard Shoulder Running (HSR) systems;

- Variable Speed limits (VSL);

- Green Islands (GIs): a multi-technological site (e.g. one for each 20-30 km highway segment) for generating energy from renewable sources (i.e. photovoltaic cells, mini-wind turbines, etc). GIs allow for a road or highway segment to be power-supplied, thus lowering operating costs. Each Green Island can be equipped with power recharge points, drone areas for landing and take-off used to survey the traffic streams and deliver the first-aid kit like, for instance, portable defibrillators;

- Electric priority lanes (lanes only for electric vehicles (EVs) [2] equipped with wireless recharge technologies);

- Charge vehicles system on specifically assigned lanes;

- Piezoelectric devices to generate electrical energy: piezoelectric crystals are placed about $5 \mathrm{~cm}$ below the asphalt pavement surface. The piezoelectric crystals 
Table 1 Summary of existing relevant studies (adapted from [7])

\begin{tabular}{lll}
\hline Study & Focus and application & Approach \\
\hline Shladover [9] & CAV platooning capacity implications & mathematical formulation \\
Vander Werf et al. [10] & CV impacts on traffic flow capacity & Monte-Carlo simulation \\
Tientrakool et al. [11] & partially AV impact on highway capacity & numerical simulation \\
Fernandes et al. [12] & CAV platooning capacity implications & traffic simulator (SUMO) \\
Shladover et al. [13] & CV impact on highway & traffic simulator (AIMSUN) \\
Milanes et al. [14] & CV impact on traffic flow stability & Empirical study \\
Arnaout et al. [15] & V2V impact & agent-based \\
Friedrich [16] & CAV impact on traffic flow condition & mathematical formulation \\
Hussain et al. [17] & CAV freeway lane management & mathematical formulation \\
Talebpour et al. [18] & CAV impact on shockwave formation & integrated simulation framework \\
Chen et al. [19] & AV impact on operational capacity & mathematical formulation \\
Ghiasi et al. [20] & CAV impact on highway capacity & Markov-chain analysis \\
Ye and Yamamoto [21] & CAV impact on traffic flow condition & numerical simulation \\
Olia et al. [22] & AV and CAV impact on highway capacity & traffic simulator (Paramics) \\
Abdulsattar et al. [7] & CAV impact on highway capacity & agent-based \\
Guerrieri et al. [8] & CAV impact on highway capacity & mathematical formulation \\
\hline
\end{tabular}

became slightly deformed when vehicles travel across the road and produce electrical current [3];

- Programmable wireless digital traffic sign systems;

- Static weighing to weigh-in-motion (WIM), virtual WIM and High speed weigh-in-motion (HS-WIM);

- Smart intersections that allow reducing fatal collisions and enhancing safety at road intersections. Using intelligent cameras, object recognition and V2X the connected vehicle can warn the driver of a pedestrian crossing, even when they are not directly within line of sight [3];

- Smart street lights with sensors-added used for a variety of purposes, including [3] (a) gunshots, terrorists and riots detection, (b) air quality monitoring, (c) EV charging points, (d) traffic congestion monitoring, (e) people crowd monitoring, (f) public safety monitoring, (g) roadside parking monitoring, and $(\mathrm{h})$ trash and littering monitoring;

- Road safety barriers equipped with an accidents monitoring system (AMS) able to detect the impacts against the barriers in real-time (e.g. NDBA safety barrier [4]).

The exchange of several types of information (i.e. position, speed, acceleration and highway alignment parameters) between the vehicles by V2V, V2I and V2X systems will enable the CAVs to anticipate the forthcoming accident risk in surroundings traffic stream resulting in accident-free and smooth driving under complex traffic environment [5].

Machine Learning (ML), Deep Learning (DL), Neural networks and in general Artificial Intelligence (AI) are highly used to increase the success rate of the emerging transportation technologies [6].
To support the public and private road operators better prepare themselves to implement C-ITS, AV, CAV technologies and smart roads in their infrastructures network, there is an urgent need to develop an integrated analysis framework to evaluate the impact of these novel systems on road capacity and safety [7].

At present, neither technical standards nor guidelines on geometric design criteria for such new digitalized infrastructures are available.

In [8] it has been formalised some novel highway design criteria founded on the performance of AVs and CAVs.

In addition, these criteria allow assessing whether an existing highway could be used by CAVs safely.

Instead, numerous studies have investigated the potential impact of CAVs on highway capacity. Generally, two different types of approach are used [7]: (i) microscopic traffic simulations; (ii) analytical models. Table 1 shows a summary of some of the most relevant literature. All the research results showed an increase in highway lane capacity in the range $180 \%-500 \%$ (Fig. 1) with correlated remarkable environmental benefits $[23,24]$.

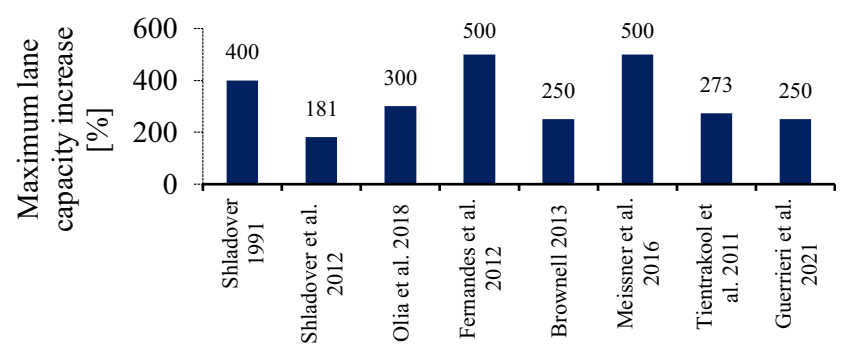

Fig. 1 Highway lane capacity increase due to smart road, AV and CAV technologies in accordance with recent research 
CAVs are still at the theoretical and experimental phases of development. In the near future different market penetration levels (MPLs) of CAVs are expected. In accordance with MPLs, different penetration rates $\eta$ of AVs and CAVs in the total highways traffic volume are plausible in the coming decades as follows:

- Market penetration level 1 (MPL1): only manually driven vehicles $(\eta=0)$;

- Market penetration level 2 (MPL2): mixed traffic flow comprising of both manually driven vehicles and CAVs $(0<\eta<1)$;

- Market penetration level 3 (MPL3): only CAVs $(\eta=1)$.

Obviously, new highways will need to be designed specifically for CAVs and existing highways will need to be able to be travelled by CAVs safely.
In this research the design and review criteria (formalised in [4]) founded on the performance of emerging $\mathrm{AV}$ and CAV technologies are used for the design review of the existing Italian A19 motorway that will be one of the first smart roads in Italy. In addition, the expected increase in motorway capacity is estimated.

The methodological approach from this research and the results of the analyzed case study may represent one of the first tools to include the emerging CAV technologies in the decision processes concerning the novel digitalizedinfrastructure planning and designing.

The remainder of the article is structured as follows: as the first section introduced the main research objectives, Sections 2 and 3 present the proposed Design criteria and capacity model for smart roads considering the effect of AVs and CAVs. In Sections 4, the proposed models are applied to the Italian A19 motorway and the results are discussed in detail.

Table 2 Horizontal and vertical design criteria in function of the market penetration levels of AVs and CAVs

\begin{tabular}{|c|c|c|c|}
\hline $\begin{array}{l}\text { Horizontal and vertical } \\
\text { design criteria }\end{array}$ & $\begin{array}{l}\text { MPL1 } \\
(\eta=0)\end{array}$ & $\begin{array}{l}\text { MPL2 } \\
(0<\eta<1)\end{array}$ & $\begin{array}{l}\text { MPL3 } \\
(\eta=1)\end{array}$ \\
\hline $\begin{array}{l}\text { Straights -Maximum } \\
\text { length }\end{array}$ & $\mathrm{L}_{\mathrm{s} \text {.max }}=22 \cdot \mathrm{V}$ & $\mathrm{L}_{\mathrm{s} \cdot \max }=22 \cdot \mathrm{V}$ & $\infty$ \\
\hline Straights -Minimum length & $\mathrm{L}_{\mathrm{s} \cdot \min }=6 \cdot \mathrm{V}$ & $\mathrm{L}_{\mathrm{s} \cdot \min }=6 \cdot \mathrm{V}$ & $\left\{\begin{array}{l}L_{s, \min }=\frac{V}{3} \\
L_{s, \min } \geq 30 \mathrm{~m}\end{array}\right.$ \\
\hline Minimum radius equation & $\frac{V^{2}}{R}=127 \cdot\left(q_{t}+f_{t}\right)$ & $\frac{V^{2}}{R}=127 \cdot\left(q_{t}+f_{t}\right)$ & $\frac{V^{2}}{R}=127 \cdot\left(q_{t}+f_{t}\right)$ \\
\hline $\begin{array}{l}\text { Horizontal curves } \\
\text {-minimum length }\end{array}$ & $S v_{\min }=2.5 \cdot \frac{V}{3.6}$ & $S v_{\min }=2.5 \cdot \frac{V}{3.6}$ & $\left\{\begin{array}{l}S_{v, \min }=\frac{V}{3} \\
S_{v, \min } \geq 30 \mathrm{~m}\end{array}\right.$ \\
\hline $\begin{array}{l}\text { Ratio between the radii of } \\
\text { consecutive horizontal } \\
\text { curves }\end{array}$ & $\begin{array}{l}\text { must fit within the "Good design area" } \\
\text { of the "radii tulip" abacus [27] (cfr. } \\
\text { Fig. 9) }\end{array}$ & $\begin{array}{l}\text { must fit within the "Good design area" } \\
\text { of the "radii tulip" abacus [27] (cfr. } \\
\text { Fig. 9) }\end{array}$ & $\begin{array}{l}\text { must fit within the "Good design area" } \\
\text { of the "radii tulip" abacus [27] } \\
\text { (cfr. Fig. 9) }\end{array}$ \\
\hline Transition curves & $\mathrm{A} 1=0.021 \mathrm{~V}^{2}$ & $\mathrm{~A} 1=0.021 \mathrm{~V}^{2}$ & $\mathrm{~A} 1=0.021 \mathrm{~V}^{2}$ \\
\hline (Clothoids paramters) & $\begin{array}{l}A 2=\sqrt{\frac{R \cdot B_{i} \cdot\left(q_{f}-q_{i}\right)}{\Delta i_{\max }}} \\
\mathrm{A} 3=\mathrm{R} / 3 \\
\mathrm{R} \geq \mathrm{A} \geq(\mathrm{A} 1, \mathrm{~A} 2, \mathrm{~A} 3)\end{array}$ & $\begin{array}{l}A 2=\sqrt{\frac{R \cdot B_{i} \cdot\left(q_{f}-q_{i}\right)}{\Delta i_{\max }}} \\
\mathrm{A} 3=\mathrm{R} / 3 \\
\mathrm{R} \geq \mathrm{A} \geq(\mathrm{A} 1, \mathrm{~A} 2, \mathrm{~A} 3)\end{array}$ & $\begin{array}{l}A 2=\sqrt{\frac{R \cdot B_{i} \cdot\left(q_{f}-q_{i}\right)}{\Delta i_{\max }}} \\
\mathrm{A} \geq(\mathrm{A} 1, \mathrm{~A} 2)\end{array}$ \\
\hline \multirow[t]{2}{*}{ Crest vertical curves } & $\begin{array}{l}R_{v}=\frac{\operatorname{SSD}_{(\mathrm{TV})}{ }^{2}}{2 \cdot\left(h_{1}+h_{2}+2 \cdot \sqrt{h_{1} \cdot h_{2}}\right)} \\
\text { if } \operatorname{SSD}_{(\mathrm{TV})}<\mathrm{L} \\
R_{v}=\frac{2}{\Delta i} \cdot\left(\mathrm{SSD}_{(\mathrm{TV})}-\frac{h_{1}+h_{2}+2 \cdot \sqrt{h_{1} \cdot h_{2}}}{\Delta i}\right) \\
\text { if } \operatorname{SSD}_{(\mathrm{TV})}>\mathrm{L} \\
\mathrm{h}_{1}=1.10 \mathrm{~m} \\
\mathrm{~h}_{2}=0.10 \mathrm{~m}\end{array}$ & & $\begin{array}{l}\text { For AV } \\
R_{v}=\frac{\operatorname{SSD}_{(\mathrm{AV})}{ }^{2}}{2 \cdot\left(h_{1}+h_{2}+2 \cdot \sqrt{h_{1} \cdot h_{2}}\right)} \\
\text { if } \operatorname{SSD}_{(\mathrm{AV})}<\mathrm{L} \\
R_{v}=\frac{2}{\Delta i} \cdot\left(\operatorname{SSD}_{(\mathrm{AV})}-\frac{h_{1}+h_{2}+2 \cdot \sqrt{h_{1} \cdot h_{2}}}{\Delta i}\right) \\
\quad \text { if } \operatorname{SSD}_{(\mathrm{AV})}>\mathrm{L} \\
\text { For } \mathrm{CAV}\end{array}$ \\
\hline & & & $\begin{array}{l}R_{v}=\frac{\operatorname{SSD}_{(\mathrm{CAV})}{ }^{2}}{2 \cdot\left(h_{1}+h_{2}+2 \cdot \sqrt{h_{1} \cdot h_{2}}\right)} \\
\text { if } \operatorname{SSD}_{(\mathrm{CAV})}<\mathrm{L} \\
R_{v}=\frac{2}{\Delta i} \cdot\left(\operatorname{SSD}_{(\mathrm{CAV})}-\frac{h_{1}+h_{2}+2 \cdot \sqrt{h_{1} \cdot h_{2}}}{\Delta i}\right) \\
\quad \text { if } \operatorname{SSD}_{(\mathrm{CAV})}>\mathrm{L} \\
\mathrm{h}_{1}>>1.10 \mathrm{~m} \\
\mathrm{~h}_{2}=0.10 \mathrm{~m}\end{array}$ \\
\hline Sag vertical curves & 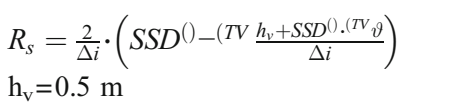 & & $R_{s} \geq 0.129 \cdot V^{2}$ \\
\hline
\end{tabular}


Finally, research conclusions, limits and prospective future studies are given in Section 5 .

\section{Smart Road Geometric Design Criteria}

In this section are given some smart road design criteria founded on the potential performance of AVs and CAVs [8]. They were obtained by modifying those traditionally employed in highway engineering in function of the so-far known potential performances of AVs and CAVs.

In accordance with Market penetration levels of CAVs three types of smart roads use have been analyzed in this research, taking into account different penetration rate $\eta$ values of CAVs in the total highways traffic volume:

- MPL1: only manually driven vehicles $(\eta=0)$;

- MPL2: mixed traffic flow comprising of both manually driven vehicles and CAVs $(0<\eta<1)$;

- MPL3: only CAVs $(\eta=1)$.

Clearly, smart roads with a mixed traffic (i.e. $0<\eta<1$ ) must ensure good safety standards as traditional road $(\eta=0)$ for considering the human factors effect deriving by traditional vehicles.

Thus the design standard of the smart roads specified for the MPL2 must be the same as those of traditional roads (i.e. MPL1).

Traditional vehicles (TVs), Autonomous Vehicles (AVs) and connected and automated vehicles (CAVs) have different reaction delay $(\mathrm{RD})$ values. In fact for TVs the reaction delay is equal to the perception-reaction time (PRT) that is correlated to Human Factors and users behaviour in Transportation Systems [25, 26]. Instead for AVs and CAVs the reaction delay is the sum of sensing, computing, communication and actuating delays and depends only by the vehicles performance.

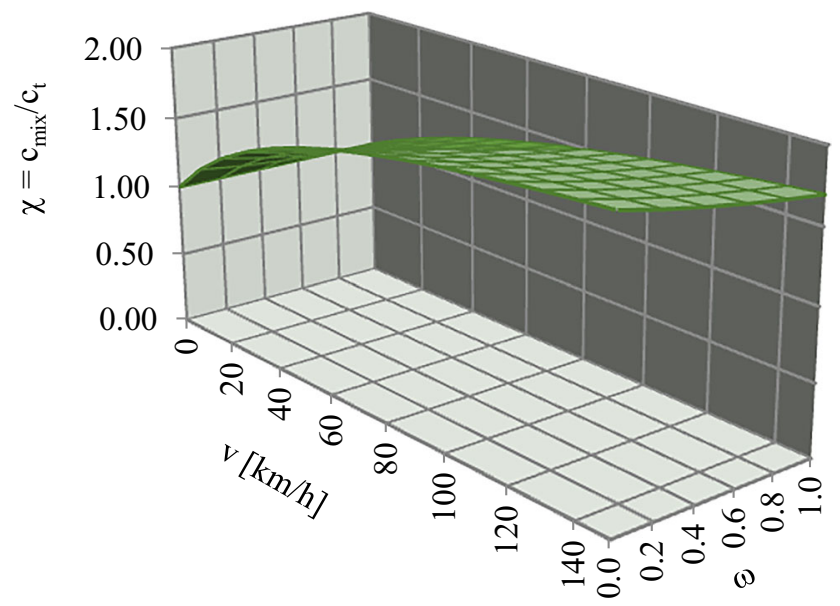

Fig. 2 Lane capacity increase $\chi$ in function of $v$ and $\omega\left(1_{m}=7.5 \mathrm{~m}\right)$
In this research the following reaction delay (expressed in seconds) are considered:

- Traditional vehicles $(\mathrm{TVs}): \mathrm{RD}=(2.8-0.01 \cdot \mathrm{V})$, being $\mathrm{V}$ the vehicle speed expressed in $\mathrm{km} / \mathrm{h}$;

- Autonomous Vehicles (AVs): $\mathrm{RD}=0.15 \mathrm{~s}$;

- Connected and automated vehicles (CAVs): $\mathrm{RD}=0.30 \mathrm{~s}$.

As it is well known the stopping sight distance (SSD) can be calculated using the following equation [25]:

$S S D=\frac{V \cdot R D}{3.6}+\frac{V^{2}}{25.92 \cdot g \cdot\left(f_{e} \pm i\right)}$

In which SSD is expressed in $\mathrm{m}, \mathrm{V}$ is the vehicle instantaneous speed in $\mathrm{km} / \mathrm{h}$, PRT is the perception-reaction time in seconds, $\mathrm{f}_{\mathrm{e}}$ is the longitudinal friction coefficient, $\mathrm{i}$ is the grade of the road.

Equation (1) allows calculating the stopping sight distance for each vehicle type using the corresponding reaction delay as follows:

- $\mathrm{SSD}_{(\mathrm{TV})}$ : stopping sight distance for Traditional Vehicle $(\mathrm{RD}=(2.8-0.01 \cdot \mathrm{V}))$;

- $\operatorname{SSD}_{(\mathrm{AV})}$ : stopping sight distance for Autonomous Vehicles $(\mathrm{RD}=0.15 \mathrm{~s})$;

- $\mathrm{SSD}_{(\mathrm{CAV})}$ : stopping sight distance for connected and automated vehicles $(\mathrm{RD}=0.30 \mathrm{~s})$.

Table 2 shows the summary of the smart road design criteria used in this research, including the design of straights, horizontal circular curves, transition curves (clothoids), crest vertical curves and sag vertical curves.

Since the research is focused on the A19 Italian motorway the design criteria of Table 2 are partially obtained in accordance with the present Italian Guidelines for the Design of Roads and Highways [28].

For more details the interested reader may consult [8].

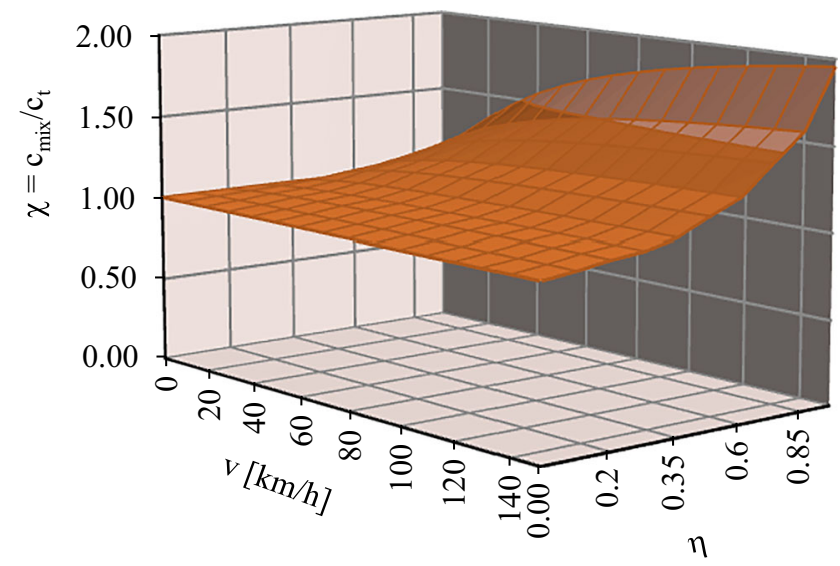

Fig. 3 Lane capacity increase $x$ in function of $v$ and $\eta$ 


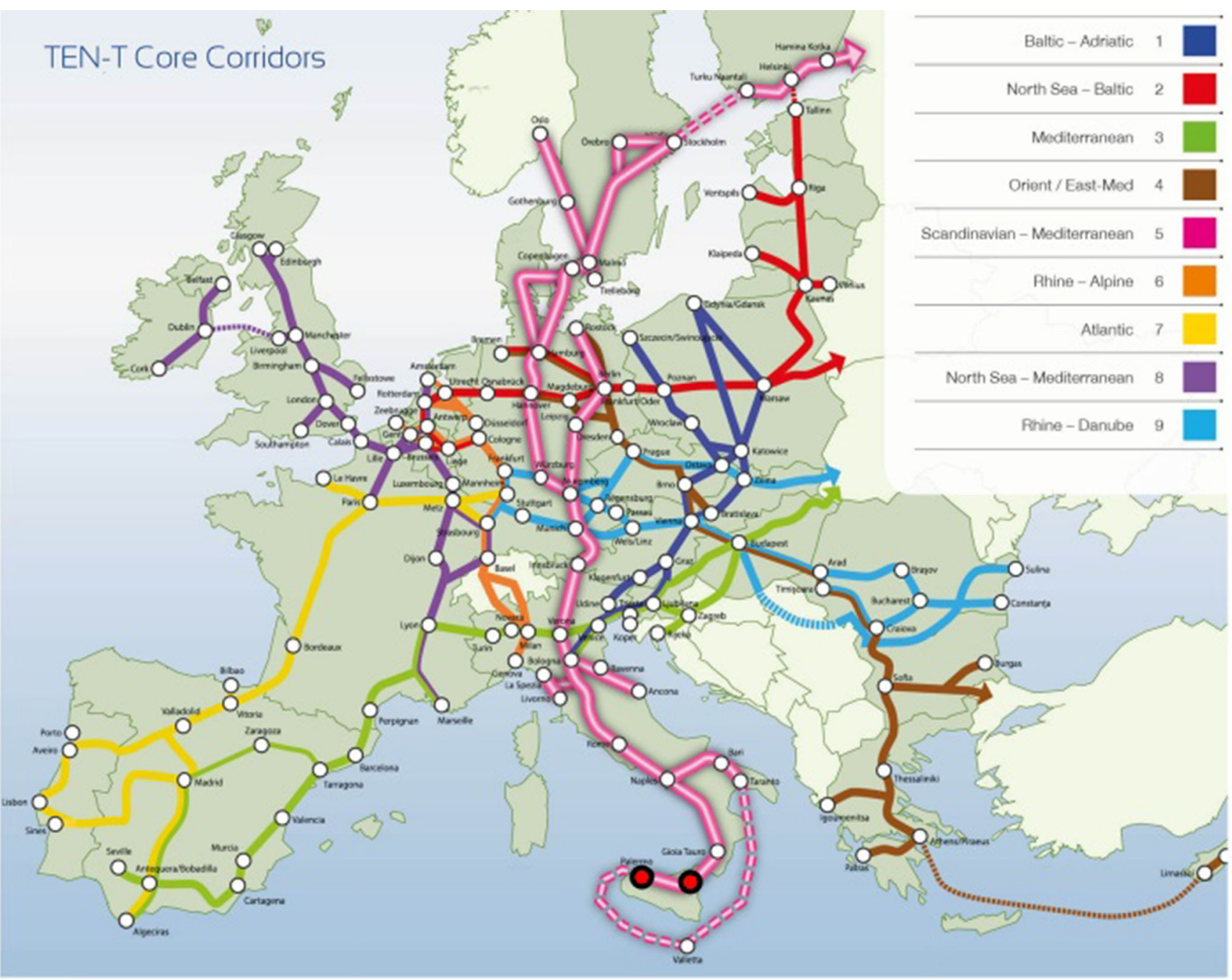

Fig. 4 TEN-T road network - the A19 motorway links the cities of Palermo and Catania (red points)

The models of Tab. 2 have been implemented in the new software "Smart Roads Safety Analysis Software. v.2021a" developed in Matlab environment and applied in this research.

\section{A Closed-Form Model for Estimating the Highway Lane Capacity Increase Due to AVs and CAVs}

As is well known, the fundamental traffic flow relationship links the macroscopic flow variables, i.e. flow q, vehicle density $\mathrm{k}$ and space mean speed $\mathrm{v}$, to each other with a state equation. In a homogeneous traffic stream the vehicle density $\mathrm{k}$ is equal to the reciprocal of the mean space gap between pairs of vehicles into the stream $[29,30]$ :

$k=\frac{1}{h \cdot v+l}$
Being $\mathrm{h}$ the mean time headway, $\mathrm{v}$ is the space mean speed and 1 is the intravehicular space distance.

In accordance with $[8,16,30-32]$ if the highway is in capacity condition for the sake of safety the following mean time headway values can be considered for traditional vehicles (TVs), Autonomous Vehicles (AVs) and connected and automated vehicles (CAVs) $[8,16]$ :

- mean time headway for TVs: $h_{t}=1.15 \mathrm{~s}$;

- mean time headway for AVs and CAVs: $h_{a}=0.5 \mathrm{~s}$.

Table 3 Main characteristics of straights (A19 motorway)

Straigthts

\begin{tabular}{lllll}
\hline $\mathrm{N}^{\circ}$ & $\mathrm{L}_{\min }[\mathrm{m}]$ & $\mathrm{L}_{\max }[\mathrm{m}]$ & $\mathrm{V}_{\mathrm{p}, \min }[\mathrm{km} / \mathrm{h}]$ & $\mathrm{V}_{\mathrm{p}, \max }[\mathrm{km} / \mathrm{h}]$ \\
\hline 169 & 56 & 2652 & 96 & 140 \\
\hline
\end{tabular}


Table 4 Main characteristics of horizontal circular curves (A19 motorway)

\begin{tabular}{lllllll}
\hline $\mathrm{N}^{\circ}$ & $\mathrm{R}_{\min }[\mathrm{m}]$ & $\mathrm{R}_{\max }[\mathrm{m}]$ & $\mathrm{V}_{\mathrm{p}, \min }[\mathrm{km} / \mathrm{h}]$ & $\mathrm{V}_{\mathrm{p}, \max }[\mathrm{km} / \mathrm{h}]$ & $\mathrm{S}_{\mathrm{v}, \min }[\mathrm{m}]$ & $\mathrm{S}_{\mathrm{v}, \max }[\mathrm{m}]$ \\
\hline 169 & 100 & 2657 & 96.39 & 140.0 & 29.83 & 2657.04 \\
\hline
\end{tabular}

The highway lane capacity is the flow value that is quite likely not to be overcome in a given highway section. In capacity conditions the mean vehicle speed is the so called critical flow speed $v_{\mathrm{c}}$. Consequently, in capacity condition $v=v_{c}$. Equation (2) enabled to estimate the capacity $c_{t}$ for a traffic stream of only Traditional Vehicles and the capacity $c_{a}$ for a stream made up of only Autonomous Vehicles (AVs) and connected and automated vehicles (CAVs) as follows:

$c_{t}=\frac{v}{h_{t} \cdot v+l}$

$c_{a}=\frac{v}{h_{a} \cdot v+l}$

The ratio $\chi$ between the two capacities is:

$\chi=\frac{c_{a}}{c_{t}}=\frac{h_{t} \cdot v+l}{h_{a} \cdot v+l}$

The traffic variable $\chi$ represents the potential increase in highways lane capacity due to the introduction of the emerging $\mathrm{AV}$ and $\mathrm{CAV}$ technologies respect to the corresponding lane capacity in case of traffic streams formed only by TVs (current technology).

The following mean values can be adopted for 1 :

- passenger car $1=1_{\text {car }}=7.5 \mathrm{~m}(4.5 \mathrm{~m}$ mean vehicle length $+3 \mathrm{~m}$ minimum safety distance to the vehicle ahead);

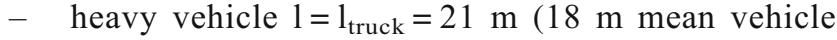
length $+3 \mathrm{~m}$ minimum safety distance to the vehicle ahead).

If mixed traffic stream condition occurs, denoting with $\omega$ the heavy vehicle share in the total highway traffic volume, for the scenario of market penetration level MPL1 $(\eta=0)$ the relationships (3), (4) and (5) can be rewritten as follows [16]:

$c_{t}=\frac{v}{(1-\omega) \cdot\left(h_{t} \cdot v+l_{\text {car }}\right)+\omega \cdot\left(h_{t} \cdot v+l_{\text {truck }}\right)}$

$c_{a}=\frac{v}{(1-\omega) \cdot\left(h_{a} \cdot v+l_{\text {car }}\right)+\omega \cdot\left(h_{a} \cdot v+l_{\text {truck }}\right)}$

$\chi=\frac{(1-\omega) \cdot\left(h_{t} \cdot v+l_{\text {car }}\right)+\omega \cdot\left(h_{t} \cdot v+l_{\text {truck }}\right)}{(1-\omega) \cdot\left(h_{a} \cdot v+l_{\text {car }}\right)+\omega \cdot\left(h_{a} \cdot v+l_{\text {truck }}\right)}$

In accordance with Eq. (8), Fig. 2 shows the highway lane capacity increases $\chi$ in function of traffic mean speed $\mathrm{v}$ and for several heavy traffic share $\omega$ values.

Consider now the market penetration levels MPL2 $(0<\eta<$ 1) and MPL3 $(\eta=1)$, being $\eta>0$ the lane capacity is a function of the penetration rate $\eta$ of AVs and CAVs in the total highways traffic volume [16]:

$c_{\text {mix }}=\frac{v}{\eta \cdot v \cdot h_{a}+(1-\eta) \cdot v \cdot h_{t}+l}$

For the future market penetration level MPL2 $(0<\eta<1)$ there will be a simultaneous presence of TVs, AVs and CAVs

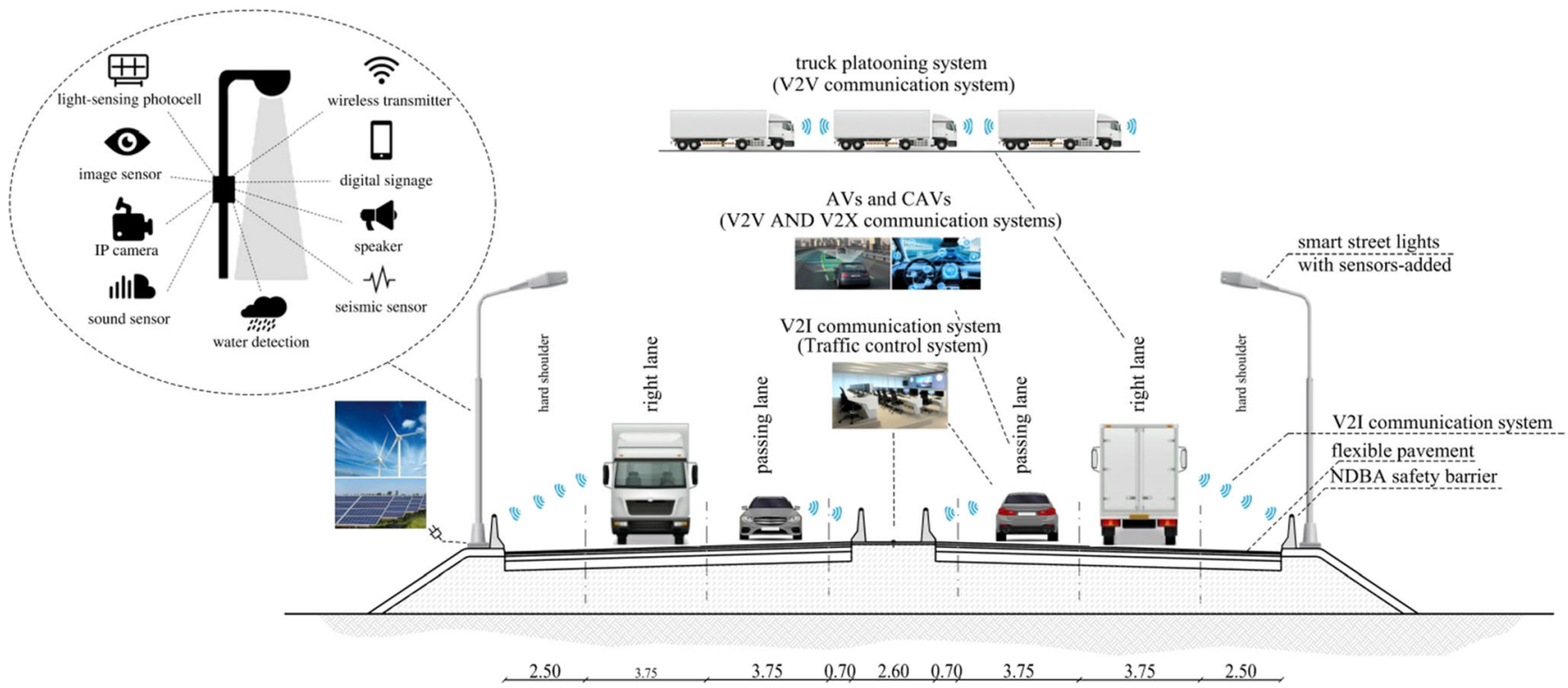

Fig. 5 A19 motorway current cross-section with exemplification of some of the planned technological devices 


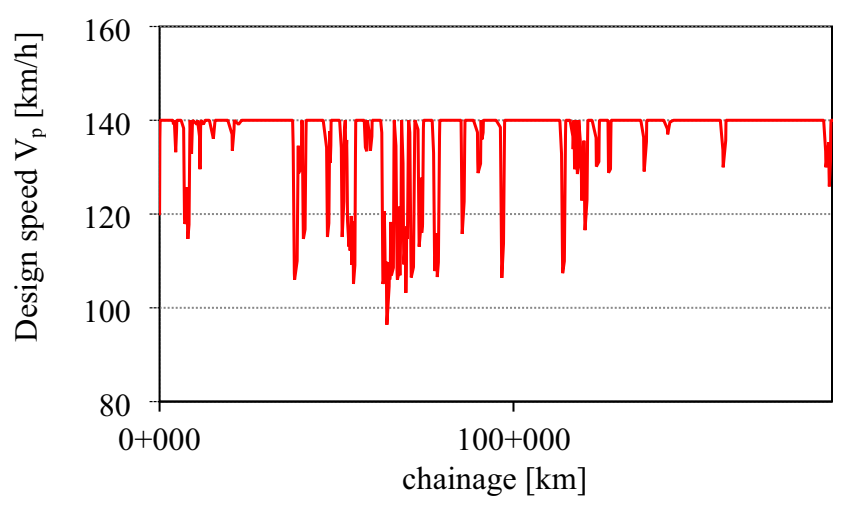

Fig. 6 Design speed diagram (A19 motorway)

therefore the vehicle pairs following one another in a certain traffic stream will be made up of a random combination of successive Traditional vehicles (TVs), Autonomous Vehicles (AVs) and connected and automated vehicles (CAVs).

In this research, depending of vehicle pairs combination, the following headways have been taken into account:

- vehicle pair TV-TV: $\mathrm{h}_{\mathrm{t}}=1.15 \mathrm{~s}$;

- vehicle pair AV-AV, CAV-CAV, AV-CAV, CAV-AV: $\mathrm{h}_{\mathrm{a}}=0.5 \mathrm{~s}$;

- vehicle pair AV-TV, CAV-TAV: $h_{a, t}=0.9 \mathrm{~s}$.

It is worth underlining that it has been assumed $h_{a, t}>h_{a}$ to preclude AVs or CAVs from travelling too close to TVs, thus disturbing the human driver of a given TV.

By denoting here with $1_{m}$ the mean vehicle length, the lane capacity can be evaluated by the following equation:

$c_{\text {mix }}=\frac{v}{\eta^{2} \cdot v \cdot h_{a}+\eta \cdot(1-\eta) \cdot v \cdot h_{a, t}+(1-\eta) \cdot v \cdot h_{t}+l_{m}}$

The ratio $\chi=\mathrm{c}_{\text {mix }} / \mathrm{c}_{\mathrm{t}}$ between the lane capacity with mixed traffic rate $\eta$ and the lane capacity with only traditional vehicles is:

$\chi=\frac{h_{t} \cdot v+l_{m}}{\eta^{2} \cdot v \cdot h_{a}+\eta \cdot(1-\eta) \cdot v \cdot h_{a, t}+(1-\eta) \cdot v \cdot h_{t}+l_{m}}$

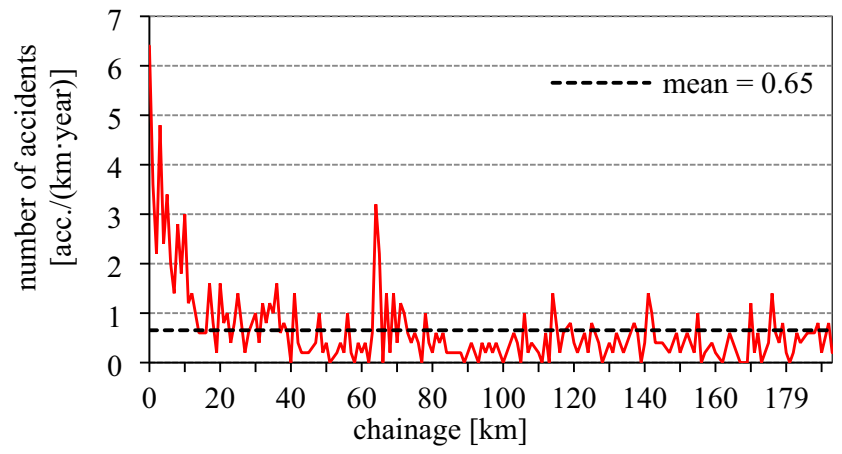

Fig. 7 Number of accidents per km and per year

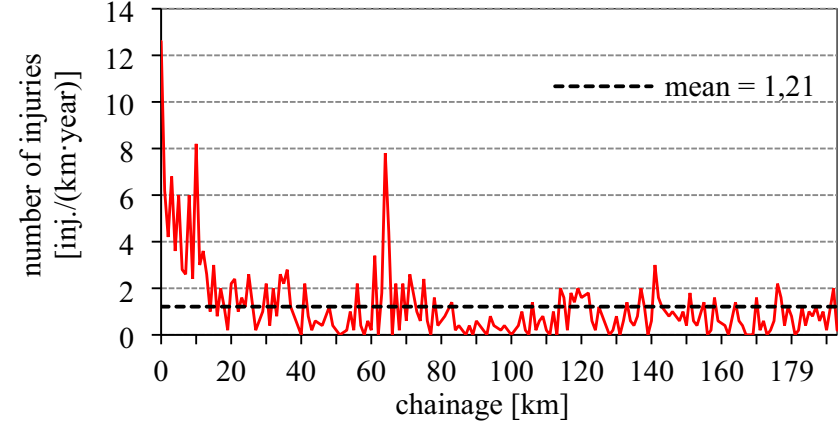

Fig. 8 Number of injuries per $\mathrm{km}$ and per year

As shown in Fig. 3 with the proposed traffic model (i.e. Friedrich model [16]) the highway lane capacity increases in proportion to the penetration rate of AVs and CAVs and decreare with the increase of the heavy vehicle share in the total highway traffic volume (Fig. 2).

\section{The Case Study of the A19 Italian Motorway}

The Italian road operator ANAS SpA in the year 2016 has launched the smart road program which involves an investment of 160 million euros for the technological modernization of the following Italian strategic infrastructures:

- the A2 "Autostrada del Mediterraneo";

- the Rome ring road A 90 and the A91 Rome-Fiumicino motorway;

- The motorway "Orte - Mestre";

- the A19 motorway' "Palermo- Catania".

In brief, the main objective of the "smart road project" is to develop digitalized infrastructures able to provide infomobility data and connectivity services. In the first phase traffic and environmental information conditions will be provided to users through innovative systems such as "wi-fi in motion" and the new DSRC (Dedicated Short Range Communications) standard.

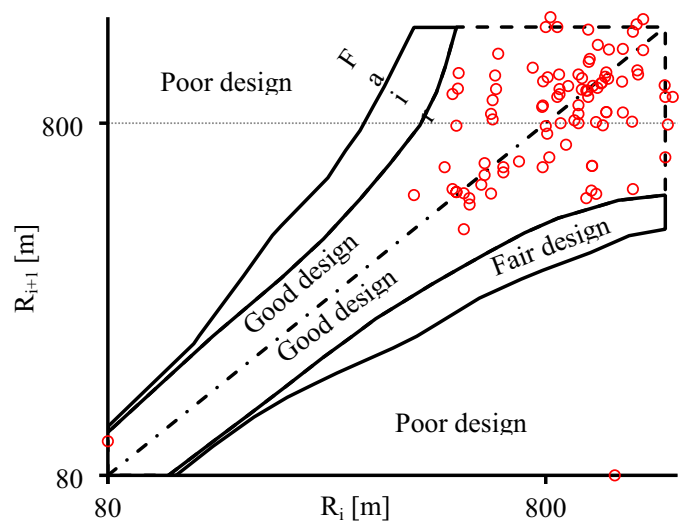

Fig. 9 Ratio between the radii of consecutive horizontal curves 


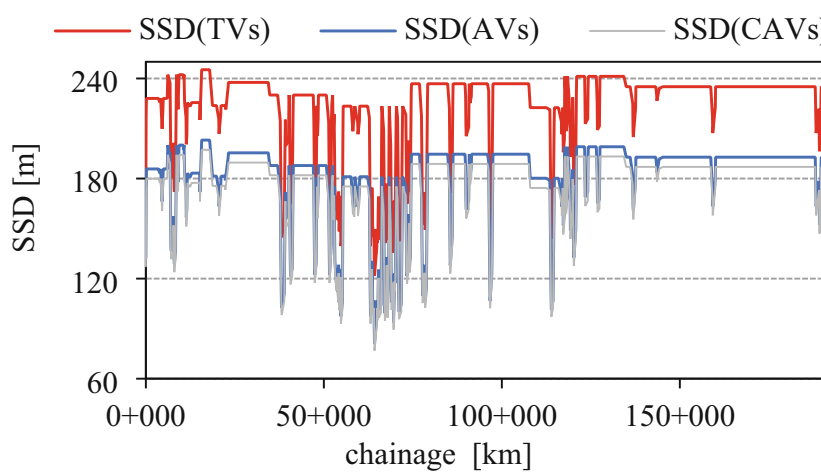

Fig. 10 Stopping sight distance profile for TVs, AVs and CAVs (direction 1: from $\mathrm{km} 0$ to $\mathrm{km} \mathrm{197)}$

The Italian A19 motorway, involved in the Italian "smart road project" belongs to the Trans-European Transport Network (TEN-T), specifically to the Helsinki-La Valletta corridor. This motorway connects the two metropolitan cities of Palermo (PA) and Catania (CT) (Fig. 4) and the cities of Caltanissetta (CL) and Enna (EN) where more than 2.8 million residents are concentrated overall, equal to over $50 \%$ of the inhabitants of the Sicily region. The study forecasts the analysis of safety and capacity implication due to the potential implementation of emerging AV and CAV technologies into the existing A19 motorway.

\subsection{Safety Evaluation}

The comprehensive geometric data on straights and circular curves of the A19 motorway are shown in Tables 3 and 4 respectively. The horizontal curves radii ranging from a minimum of $100 \mathrm{~m}$ to a maximum of $2657 \mathrm{~m}$. The grade values are modest for the entire infrastructure $(0 \% \leq|\mathrm{i}| \leq 3.7 \%)$.

Currently the A19 motorway is $197-\mathrm{km}$ long. It has two lanes (3.75-m wide each) in each direction and right-hand hard shoulders, each $2.50 \mathrm{~m}$-wide; the mean wide of the central reservation is $4.00 \mathrm{~m}$ (see Fig. 5).

Figure 6 shows the design speed diagram deducted for the analyzed motorway. Several researchers have used speed (design speed $V_{p}$ and operating speed $V_{85}$ ) as surrogate measure to evaluate road consistency and safety [33-35].

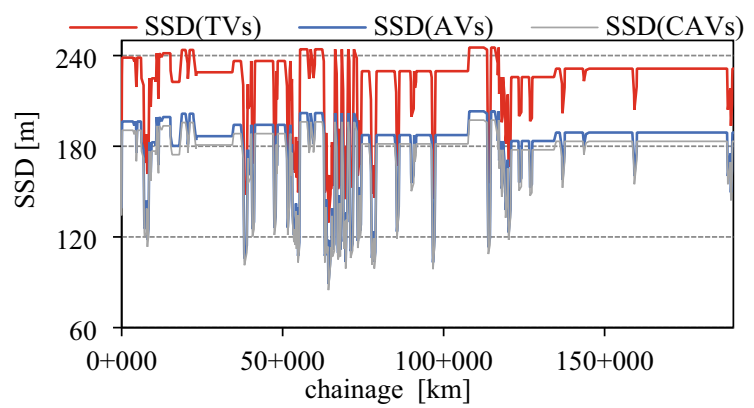

Fig. 11 Stopping sight distance profile for TVs, AVs and CAVs (direction 2: from $\mathrm{km} 197$ to $\mathrm{km} \mathrm{0)}$
Table 5 Locations of counting sections

\begin{tabular}{ll}
\hline Counting section & Location \\
\hline $\mathrm{km} 6+283$ & Bagheria (PA) \\
$\mathrm{km} 10+900$ & Altavilla Milicia (PA) \\
$\mathrm{km} 80+100$ & Resuttano (CL) \\
$\mathrm{km} 92+112$, & Alimena (PA) \\
$\mathrm{km} 112+500$, & Enna (EN) \\
$\mathrm{km} 157+300$ & Catenanuova (EN) \\
$\mathrm{km} 188+848$ & Misterbianco (CT) \\
\hline
\end{tabular}

In accordance with the Italiana road and highway design guidelines [28], the design speed profile allows evaluating the consistency of highway alignment elements. A good consistency ensures safe driving conditions at the desired speed on the entire highway segment, while the inconsistency is manifested when drivers must slow down below the desired speed to safely connect to the next road element [36]. Therefore, its knowledge is crucial because it allows assessing the potential heterogeneity of the alignment also in case of existing roads. For the A19 motorway the design speed values are in the range $96.39-140.00 \mathrm{~km} / \mathrm{h}$, but the speed variation between consecutive geometric elements (e.g. tangent to curve and curve to curve) is always below $10 \mathrm{~km} / \mathrm{h}$.

In order to deeply understand the current safety conditions of the A19 motorway before implementing smart road, AV and CAV technologies, crash occurrences have been analyzed collecting ANAS Spa reports. Crash data covered a time period of 5 years (2012-2016).

In this interval of time crash count was 634 , the mean number of accidents and injuries per year and kilometer were 0.65 and 1.21 respectively.

The data pointed out that accidents more frequently occurred in the motorway segments next to the City of Palermo (km 0, Figs. 7 and 8) where high traffic flow values have been recorded (AADT $=76.289 \mathrm{veh} /$ day, see Tab. 6).

The analyses show that the horizontal and vertical overall alignment of the A19 motorway is in compliance with the design and the review criteria discussed in Sect. 2. For instance, Fig. 9 demonstrates that the ratio between the radii of consecutive horizontal curves almost always falls in the good design zone of the "radii tulip" abacus [27, 37]. Only some straights are shorter than the minimum values shown in Tab. 2. However "short" straights may generate only potential comfort issues for users and not safety issues. In fact AVs and CAVs will be capable to regulate their acceleration, deceleration and speed in function of the motorway alignment using the information and exchange data between the existing infrastructure and vehicles tanks to the emerging V2I and I2V communication systems [38-40]. Also the research results demonstrate that Autonomous Vehicles and connected and 


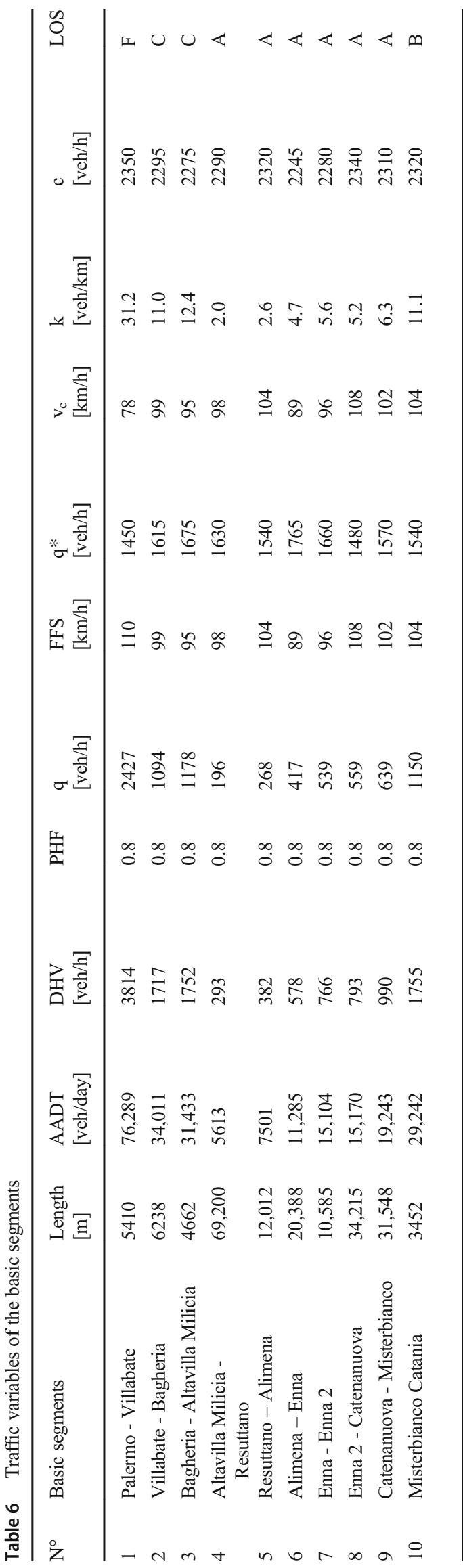

automated vehicles will necessitate shorter stopping sight distances (SSD) than those required by traditional vehicles. In fact, Figs. 10 and 11 clarify that in each motorway direction and section it results:

- $\operatorname{SSD}_{(\mathrm{AV})}<\mathrm{SSD}_{(\mathrm{TV})}$

- $\operatorname{SSD}_{(\mathrm{CAV})}<\mathrm{SSD}_{(\mathrm{TV})}$.

The previous conditions on the stopping sight distances may help to remove various existing speed limits in particular infrastructure segments (generally used to visibility obstacles) with consequent benefits in terms of travel time (TT) reduction and Level of Service (LOS) improvement.

\subsection{Capacity Estimation}

The prominent counting section chosen to carry out the traffic analyses are given in Table 5. The examined traffic data were collected from 1th January to 31 th December 2015.

Table 6 shows for each of the ten homogeneous basic segments in which the A19 motorway has been subdivided the traffic parameters in terms of Annual Average Daily Traffic (AADT), peak hour factor (PHF) and Design Hourly Volume (DHV). Each basic segment is characterized by a constant AADT value.

The Free flow speed (FFS) of the motorway segments were measured directly by the counting sections of Tab. 5. By means of the HCM model [41] the Speed-Flow curve v = $v(q)$ for each basic segment has been estimated using the following Equations:

$\left\{\begin{array}{l}\mathrm{v}=F F S \\ \text { if } \mathrm{q}<\mathrm{q}^{*} \quad \text { with } \quad \mathrm{q}^{*}=3100-15 \cdot F F S\end{array}\right.$
$\left\{\begin{array}{l}\mathrm{v}=\mathrm{F} F S-\left[\frac{1}{28} \cdot(23 \cdot \mathrm{F} F S-1800) \cdot\left(\frac{\mathrm{q}+15 \cdot \mathrm{F} F S-3100}{20 \cdot \mathrm{FFS}-1300}\right)^{2.6}\right. \\ \text { if } \mathrm{q}^{*}<q \leq \mathrm{c} \quad \text { with } \quad \mathrm{c}=1800+5 \cdot \mathrm{FFS}\end{array}\right.$

Figure 12 illustrates the Speed-flow curves with the representation of LOS limits for each basic segment. The lane capacity ranging from a minimum of $2275 \mathrm{veh} / \mathrm{h}$ to a maximum of $2350 \mathrm{veh} / \mathrm{h}$ depending on the motorway basic segment (Tab. 6), instead the critical speed $v_{c}$ values fall in the field $\mathrm{v}_{\mathrm{c}}=78-108 \mathrm{~km} / \mathrm{h}$ depending on the basic segment. As shown in Table 6 the levels of service are good for the entire motorway (LOS A-LOS C) except for the first basic segment (Palermo-Villabate) where oversaturation phenomena have been detected (LOS F). These results can be considered reliable not only for the existing configuration of the A19 motorway but also for the case of market penetration level 1 (only TVs and $\eta=0$ ).

A quantitative estimation of the effects deriving by the implementation of emerging smart road, AV and CAV 


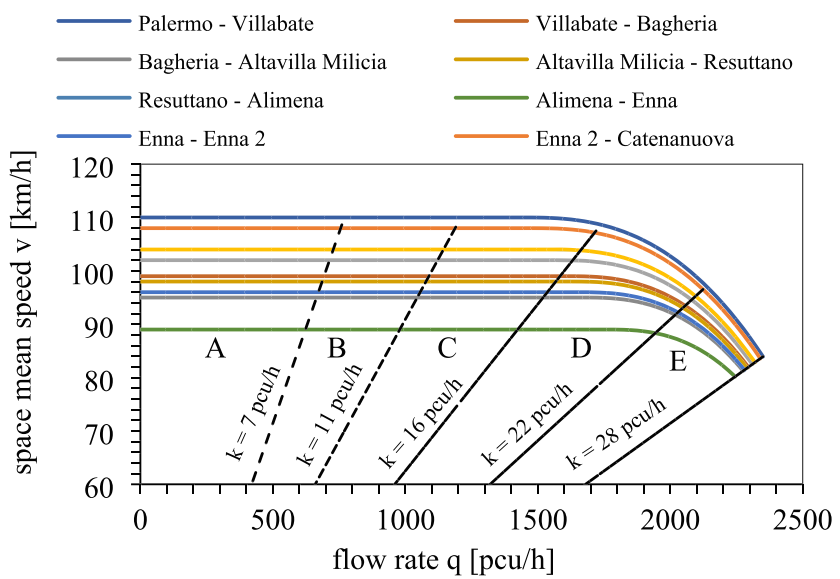

Fig. 12 Speed-flow curves with representation of LOS limits for each basic segment of the A19 motorway

technologies on capacity of each motorway segment can be assessed using the proposed model in Sect. 3.

As explained in Sect. 2, the expected lane capacity increase is a function of penetration rate $\eta$ of AVs and CAVs in the total traffic volume.

Eq. (10) can be applied to estimate, for each basic segment of Tab. 6 , the potential capacity value with mixed traffic $\mathrm{c}_{\text {mix }}$ and the ratio $\chi=\mathrm{c}_{\text {mix }} / \mathrm{c}_{\mathrm{t}}$ between such a potential capacity and that estimated in the present traffic conditions $\left(c_{t}\right)$ or in case of market penetration level 1 (i.e. TVs, therefore $\eta=0$ ). Figure 13 shows the typical diagrams of the variable $\chi$ as a function of the penetration rate $\eta$ of AVs and CAVs for the all the basic segments.

As expected, lane capacity increase more and more with the increase of the penetration rate $\eta$. It is worth pointing out that for $\eta=1$ (i.e. MPL3) the infrastructure will be used only by AVs and CAVs. In this particular traffic flow condition $(\eta=1)$, the potential lane capacity values ranging from a minimum of $4336 \mathrm{veh} / \mathrm{h}$ to a

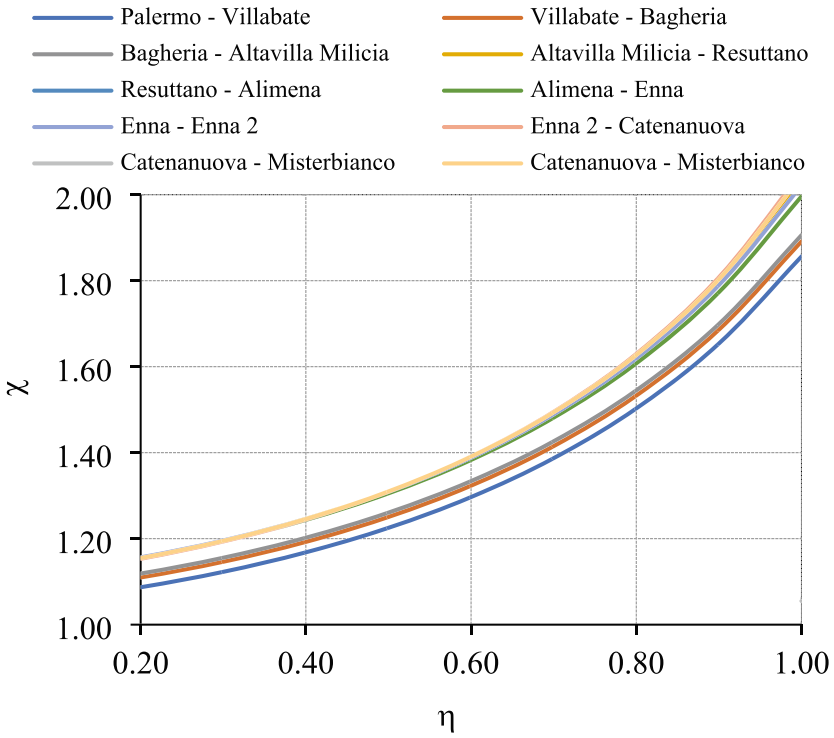

Fig. 13 Ratio $\chi$ as a function of $\eta$ for each basic segment of the A19 motorway maximum of $4800 \mathrm{veh} / \mathrm{h}$ (Fig. 14) against the current capacity range of $2275 \mathrm{veh} / \mathrm{h}-2350 \mathrm{veh} / \mathrm{h}(\eta=0)$. Therefore, the expected potential percentage improvement in the lane capacity may reach values in the range $186 \%-205 \%$ respect to the current lane capacity $(\eta=0)$, depending on the motorway basic segment.

\section{Conclusions}

Smart road, Autonomous Vehicles (AVs) and connected and automated vehicles (CAVs) are emerging technologies that allow increasing road capacity, and safety. In particular, smart roads are digitalized infrastructures well-matched with $\mathrm{AVs}$ and CAVs tanks to the V2V and V2I communication systems.

To support the public and private road operators better prepare themselves to implement these emerging technologies in the existing roads and highways, there is an urgent need to develop an integrated analysis framework to assess the influence of the already mentioned technologies on road capacity and safety in function of market penetration (MP) levels of AVs and CAVs. In this regards, three different modes of smart roads use have been analyzed in this research, considering different penetration rates of CAVs in the total highways traffic volume:

- MPL1: only manually driven vehicles $(\eta=0)$;

- MPL2: mixed traffic flow comprising of both manually driven vehicles and CAVs $(0<\eta<1)$;

- MPL3: only CAVs $(\eta=1)$.

In this article some novel highway geometric design and review criteria established taking into account the performance of emerging $\mathrm{AV}$ and $\mathrm{CAV}$ technologies are used for the design review of the existing Italian A19 motorway that will be one of the first smart roads in Italy. Nowadays the A19 motorway is part of the Trans-European Transport Network TEN-T (specifically the Helsinki-La Valletta corridor). The proposed highways and road design criteria are partially based on the Italian Guidelines for the Design of Roads and Highways and may represent a useful support tool for decision making.

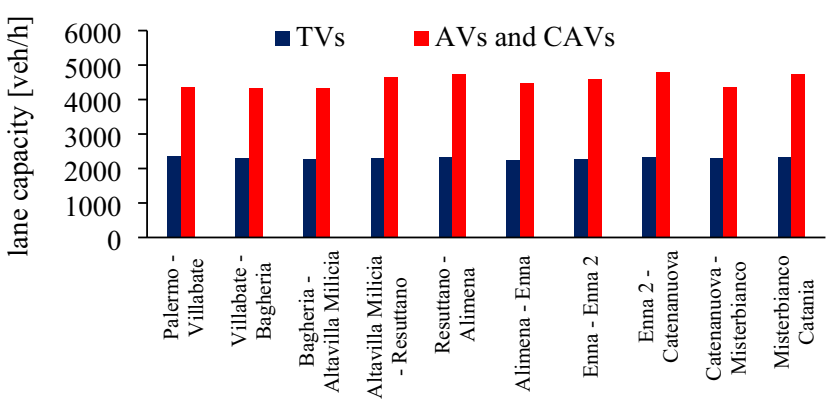

Fig. 14 Estimated lane capacity for each basic segments in the current traffic conditions (only TVs) and for the MPL3 (only AVs and CAVs) 
The proposed criteria have been implemented in the new software "Smart Roads Safety Analysis Software. v.2021a" developed in Matlab environment and used for analyzing the A19 motorway.

Although the A19 motorway was built several decades ago, the analyses concerning its geometric alignment show that the infrastructure is in compliance with the proposed highway geometric design and review criteria except for only some geometric elements (straights). In addition, the research results demonstrate that AVs and CAVs will necessitate shorter stopping sight distances (SSD) than those required by traditional vehicles (TVs), therefore many existing speed limits in particular motorway segments (as in the case of the A19) could be removed when Market Penetration Level MPL3 $(\eta=1)$ will be concretely achieved with consequential benefits in terms of travel time reduction and LOS improvement.

Also the research focuses on the comparative analysis of the current motorway capacity and the future capacity due to the implementation of smart road, AV and CAV merging technologies.

First, the A19 motorway was subdivide in ten homogeneous basic segments characterized by a constant AADT value. Then, the Speed-flow curves with the representation of LOS limits for each basic segment have been deduced staring from a sample of traffic data collected from 1th January to 31 th December 2015.

Instead, the estimation of the effects deriving by the implementation of emerging smart road, AV and CAV technologies on capacity of each motorway segment was obtained by the Friedrich model.

As predictable, the motorway lanes capacity growth increasing of the penetration rate $\eta$ of AVs and CAVs in the total highways traffic volume. For instance for $\eta=1$ (i.e. MPL3) the potential lane capacity values ranging from a minimum of 4336 $\mathrm{veh} / \mathrm{h}$ to a maximum of $4800 \mathrm{veh} / \mathrm{h}$, depending on the basic segment, against the current capacity range of $2275 \mathrm{veh} / \mathrm{h}-$ $2350 \mathrm{veh} / \mathrm{h}(\eta=0$, i.e. MPL1). Then, in accordance with the main results of the present research, for the case of MPL3, the expected potential percentage improvement in the lane capacity may reach values up to $205 \%$ respect to the current lane capacity.

In conclusion, the study aims to cover the research gap in the field of smart roads geometric design and capacity estimation. It is worth underlining that the results of this study are affected to the hypotheses assumed in the proposed and adopted closed-form models in particular as concern the potential performances of AVs and CAVs. Therefore, the closed-form models from this research and the main results of the analyzed case study may represent only one of the first tools to include the emerging Smart road, AVs and CAVs technologies in the decision processes concerning the novel digitalized-road planning and designing.

More reliable mathematical models could be considered in future researches as well as the study of the effect of emerging technologies on other geometric design parameters of smart roads (e.g. the lane widths which may be smaller than those currently used) and the sustainability of such innovative transportation systems.

List of Abbreviations and Nomenclature $A$, clothoid parameter; $A_{l}$, clothoid parameter (dynamic criterion); $A_{2}$, clothoid parameter (slope criterion); $A_{3}$, clothoid parameter (optical criterion); $A V$, autonomous Vehicle; $B_{i}$, carriageway width; $c_{t}$, lane capacity for traffic stream of only $\mathrm{TVs} ; c_{a}$, lane capacity for traffic stream of only AVs and CAVs; $C A V$, connected and automated vehicle; $\Delta i$, total grade change; $\Delta_{\text {imax }}$, denotes the maximum gradient edge of the clothoid arc; $f_{e}$, longitudinal friction factor; $f_{t}$, side friction factor; $F F S$, free flow speed; $h_{l}$, height of driver's eye point; $h_{2}$, target point (object) height; $h_{v}$, vehicle headlights height; $\eta$, penetration rate of CAVs respect to the total traffic volume; $k$, vehicle density; $L O S$, level of service; $L_{s . m a x}$, maximum straight length; $L_{s . m i n}$, minimum straights length; $M P L$, market penetration level of AVs and CAVs; $q$, traffic flow; $q_{t}$, circular curve superelevation; $q_{f}$, superelevation at the end of the clothoid; $q_{i}$, superelevation at the beginning of the clothoid; $\theta$, vehicle headlights divergence; $R$, horizontal circular radius; $R_{v}$, minimum crest radius; $R_{s}$, sag vertical curve design; $R D$, reaction delay; $S S D$, the stopping sight distance; $S_{v, \text { min }}$, minimum length of the circular horizontal curve; $T T$, travel time; $V$, vehicle speed; $v$, vehicle space mean speed; $v_{c}$, critical speed (of traffic flow); $V_{p}$, design speed

Acknowledgments The author wishes to thank Prof. Raffaele Mauro and Ph.D. Eng Giuseppe Parla for their contribution to the development of the research.

Funding Open access funding provided by Università degli Studi di Trento within the CRUI-CARE Agreement.

\section{References}

1. Guerrieri, M., Mauro, R.: Traffic management and control systems. Springer Tracts in Civil Engineering, 103-129 (2021)

2. Macioszek, E.: Electric vehicles - problems and issues. Advances in Intelligent Systems and Computing. 1091, 169-183 (2020)

3. Toh, C.K., Sanguesa, J.A., Cano, J.C., Martinez, F.J.: Advances in smart roads for future smart cities. Proceedings of the Royal Society A: Mathematical, Physical and Engineering Sciences. 476(2233), (2020)

4. Dinnella, N., Chiappone, S., Guerrieri, M.: The innovative "NDBA" concrete safety barrier able to withstand two subsequent TB81 crash tests. Engineering Failure Analysis, 115(2020)

5. Treiber, M., Kesting, A., Helbing, D.: Delays, inaccuracies and anticipation in microscopic traffic models. Physica A. 360(1), 71-88 (2006)

6. Bhogaraju, S.D., Korupalli, V.R.K.: Design of smart roads - a vision on indian smart infrastructure development. 2020 International conference on COMmunication systems and NETworkS, COMSNETS, 773-778 (2020)

7. Abdulsattar, H., Siam, M.R.K., Wang, H.: Characterisation of the impacts of autonomous driving on highway capacity in a mixed traffic environment: An agent-based approach. IET Intelligent Transport Systems. 14(9), 132-1141 (2020)

8. Guerrieri, M., Mauro, R., Isaenko, N., Pompigna, A.: Road design criteria and capacity estimation based on autonomous vehicles performances. First results from the European C-Roads platform and A22 motorway. Transport and Telecommunication. 2, (2021)

9. Shladover, S.E.: Potential freeway capacity effects of automatic vehicle control systems, applications of advanced technologies in 
transportation engineering, ASCE Conference, Minneapolis, MN, 213-217 (1991)

10. Vander Werf, J., Shladover, S., Miller, M., et al.: Effects of adaptive cruise control systems on highway traffic flow capacity. Transp. Res. Rec. 1800(1), 78-84 (2002)

11. Tientrakool, P., Ho, Y.C., Maxemchuk, N.F.: Highway capacity benefits from using vehicle-to-vehicle communication and sensors for collision avoidance. IEEE Vehicular Technology Conf. (VTC FALL), San Francisco, CA, USA, 1-5. (2011)

12. Fernandes, P., Nunes, U.: Platooning with ivc-enabled autonomous vehicles: strategies to mitigate communication delays, improve safety and traffic flow. IEEE Trans. Intell. Transp. Syst. 13(1), 91-106 (2012)

13. Shladover, S.E., Su, D., Lu, X.-Y.: Impacts of cooperative adaptive cruise control on freeway traffic flow. Transp. Res. Rec. 2324(1), 63-70 (2012)

14. Milanés, V., Shladover, S.E., Spring, J., et al.: Cooperative adaptive cruise control in real traffic situations. IEEE Trans. Intell. Transp. Syst. 15, 296-305 (2013)

15. Arnaout, G.M., Bowling, S.: A progressive deployment strategy for cooperative adaptive cruise control to improve traffic dynamics. Int. J. Autom. Comput. 11(1), 10-18 (2014)

16. Friedrich, B.: The effect of autonomous vehicles on traffic. In: Maurer M., Gerdes J., Lenz B., Winner H. (eds) Autonomous Driving, Springer (2016)

17. Hussain, O., Ghiasi, A., Li, X.: Freeway lane management approach in mixed traffic environment with connected autonomous vehicles. arXivpreprint arXiv:1609.02946, 2016

18. Talebpour, A., Mahmassani, H.S.: Influence of connected and autonomous vehicles on traffic flow stability and throughput. Transp. Res. C, Emerg. Technol. 71, 143-163 (2016)

19. Chen, Y., Zha, J., Wang, J.: An autonomous T-intersection driving strategy considering oncoming vehicles based on connected vehicle technology. IEEE/ASME Trans. Mechatronics. 24(6), 2779-2790 (2019)

20. Ghiasi, A., Hussain, O., Qian, Z.S., et al.: A mixed traffic capacity analysis and lane management model for connected automated vehicles: A markov chain method. Transp. Res. B, Methodol. 106, 266-292 (2017)

21. Ye, L., Yamamoto, T.: Modeling connected and autonomous vehicles in heterogeneous traffic flow. Physica A. 490, 269-277 (2018)

22. Olia, A., Razavi, S., Abdulhai, B., Abdelgawad, H.: Traffic capacity implications of automated vehicles mixed with regular vehicles. J. Intell. Transp. Syst. 22(3), 244-262 (2018)

23. Guerrieri, M., Corriere, F., Rizzo, G., Lo Casto, B., Scaccianoce, G.: Improving the sustainability of transportation: environmental and functional benefits of right turn by-pass lanes at roundabouts. Sustainability (Switzerland). 7(5), 5838-5856 (2015)

24. Guerrieri, M., Corriere, F., Parla, G., Ticali, D.: Estimation of pollutant emissions from road traffic by image processing techniques: a case study in a suburban area. ARPN Journal of Engineering and Applied Sciences. 8(8), 668-676 (2013)

25. NCHRP, Report 600. Human factors guidelines for road systems, second edition. Transportation Research Board, National Cooperative Highway Research Program (2012)

26. Guerrieri, M., Mauro, R., Parla, G., Tollazzi, T.: Analysis of kinematic parameters and driver behavior at turbo roundabouts. Journal of Transportation Engineering Part A: Systems. 144(6), (2018)

27. German Guidelines for the Design of Roads and Highways (Die Richtlinien für die Anlage von Straßen - Teil: Linienführung, kurz RAS-L), Germany, (1995)

28. Italian Guidelines for the Design of Roads and Highways (D.M. $5 / 11 / 2001$, in Italian)

29. Ioannou, A.: Automated highway systems. Springer. (1997)

30. Elefteriadou, L.: An introduction to traffic flow. Springer (2014)
31. Carbaugh, J., Godbole, D.N., Sengupta, R.: Safety and capacity analysis of automated and manual highway systems. Transportation Research Part C: Emerging Technologies. 6(1-2), 69-99 (1998)

32. Dixit, V.V., Chand, S., Nair, D.J.: Autonomous vehicles: disengagements, accidents and reaction times. PLoS One. 20, 1-14 (2016)

33. Hassan, Y. and Sarhan, M.: Modeling operating speed: synthesis report. Chapter 1: Introduction. Transportation Research ECircular, (E-C151) (2011)

34. Lamm, R., Choueiri, E. M., and Mailaender, T.: Comparison of operating speed on dry and wet pavement of two lane rural highways. Transp. Res. Rec. 1280, Transportation Research Board, Washington, D.C., 199-207 (1990)

35. Lamm R., Psarianos, B., Chourieri, E. M., Soilemezoglou, G.: A pratical safety approach to highway geometric design. International case studies: Geramn, Greece, Lebanon and the United States. International Symposium on Highway Geometric Design, 9:1-9:14 (1995)

36. Cvitanić, D., Vukoje, B., Breški, D.: Methods for Ensuring Consistency of Horizontal Alignment Elements Gradjevinar, 64 (5), 385-393 (2012)

37. Lamm, R.: Highway design and traffic safety engineering handbook. McGraw-Hill Education. (1999)

38. Chang, T.-H.: Improving highway design to enhance the performance of automated highway systems. ITS Journal, 4 (3), (1999)

39. Chang, T.-H., Wang, M.-C., Yu, S.-M.: Advance-F automatic car following model and its traffic characteristics. International Journal of Automotive Technology. 12(6), 933-942 (2011)

40. Chang, T.-H., Lai, I.-S.: Analysis of characteristics of mixed traffic flow of autopilot vehicles and manual vehicles. Transportation Research Part C: Emerging Technologies. 5(6), 333-348 (1997)

41. TRB. Highway Capacity Manual, 5th ed. Washington, DC, USA (2010)

42. Brownell, C.K.: Shared autonomous taxi networks: An analysis of transportation demand in nj and a 21st century solution for congestion. Princeton University, (2013).

43. Meissner, E., Chantem, T., Heaslip, K.: Optimizing departures of automated vehicles from highways while maintaining mainline capacity. IEEE Trans. Intell. Transp. Syst. 17, 3498-3511, (2016).

Publisher's Note Springer Nature remains neutral with regard to jurisdictional claims in published maps and institutional affiliations.

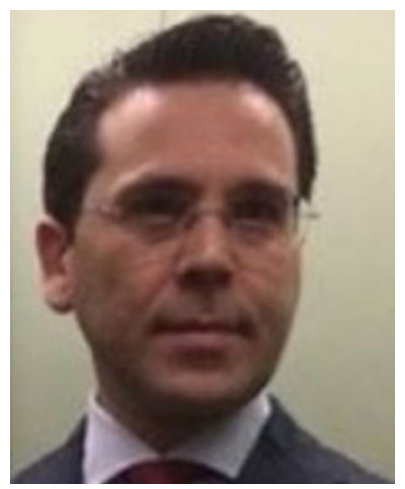

Marco Guerrieri Assistant Professor at DICAM University of Trento (Italy) and qualified as Full Professor by the Italian National Scientific Habilitation. $\mathrm{He}$ received the $\mathrm{PhD}$ in Highway Engineering in 2006. He is author of over 100 scientific papers, 2 books and 2 patents of invention. 